\title{
An ecological worldview as basis for a regenerative sustainability paradigm for the built environment
}

Chrisna Du Plessis ${ }^{\mathrm{a}}$ and Peter Brandon ${ }^{\mathrm{b}}$

\author{
a Department of Construction Economics, University of Pretoria, Private Bag X20, Hatfield, 0028, South Africa, \\ chrisna.duplessis@up.ac.za(corresponding author) \\ ${ }^{\mathrm{b}}$ School of the Built Environment, University of Salford, Salford, M5 4WT, UK \\ p.s.brandon@salford.ac.uk
}

This paper was published as:

Du Plessis, C. and Brandon, P.S. 2015. An ecological worldview as basis for a regenerative sustainability paradigm for the built environment. Journal of Cleaner Production, 109:53-61.

\begin{abstract}
It has been widely argued that in order to move development into a positive curve towards sustainability, society needs to change the worldview/paradigm within which it currently operates; and that such a shift from a mechanistic to an ecological/living systems worldview is already happening. It is suggested that the purpose of the sustainability paradigm flowing from this worldview is not to conserve the status quo or meet ill-defined human needs, but to strengthen the health, adaptive capacity, and evolutionary potential of the fully integrated global social-ecological system so that it can continue regenerating itself, thereby creating the conditions for a thriving and abundant future - not only for the human species, but for all life. In this paper we explore the ecological worldview and the guidelines it provides for how we interpret sustainability; as well as the strategies for the production of the built environment we need to follow if we are to adapt to coming changes in the planetary system and regenerate the world. The question this paper asks is: how does this sustainability paradigm, with its focus on regenerating the whole of the socialecological system within which we are working, change the way the built environment is produced? To achieve this objective, the paper synthesizes the findings of two separate studies: an extensive literature review to define the meta-narratives of the ecological worldview; and an analysis of in depth interviews with academics and built environment practitioners that aimed to find correlations between the practice and theoretical positions of the participants and the values and praxiology of the ecological worldview as described in the first study. Three main themes of the ecological worldview - wholeness, relationship, and change - provide a framework for discussing the implications of this regenerative sustainability paradigm for the production of the built environment - for how it is created, the technologies used, and how it is evaluated.
\end{abstract}

\section{Keywords:}

Worldview, ecology, regenerative, resilience, biophilia, holistic. 


\section{Introduction}

Thomas Kuhn, in his book the Structure of Scientific Revolutions (Kuhn, 1970), argues that the history of science demonstrates that it is marked by periods of 'normative science' interspersed with periods of rapid change where the paradigm of our culture, and indeed the current body of scientific knowledge, is broken. A new paradigm is created, which then becomes established and the circle begins again. His intention was to break the naive belief in the great chain of unbroken progress and perpetual revolution to which most scientists subscribed. Although his work has been debated by many, and particularly the followers of Karl Popper in the context of his understanding of the growth of knowledge (Popper, 1963 and 2004), it is still held to be true by many. New knowledge, new thinking, new technology is built by developing successful ideas based on a set of premises and values which remain true until they are challenged.

In the context of sustainable development it would appear that we are facing such a paradigm shift. It has been widely argued that in order to move development into a positive curve towards sustainability (and further into what some call thrivability), society needs to change the worldview/paradigm within which it currently operates, and that such a worldview shift is already happening. Edwards (2005:5) describes sustainability as "a revolution with a new value system, consciousness and worldview". Orr (2005:xiv) further describes this 'sustainability revolution' as "...nothing less than a rethinking and remaking of our role in the natural world. It is a recalibration of human intentions to coincide with the way the biophysical world works". Reed (2007:675) suggests that this new sustainability paradigm goes beyond current notions of increased resource efficiency and reduced impact while meeting basic needs, to being based on the idea of whole or livingsystems thinking, in which the "purpose of sustainability is sustaining life-enhancing conditions". He proposes the following trajectory of increasingly whole approaches (ibid.: 677):

- restorative approaches that "restore the capacity of local natural systems to a healthy state of self-organisation";

- reconciliatory approaches which "acknowledge "that humans are an integral part of nature and that human and natural systems are one"; and

- regenerative approaches that engage and focus "on the evolution of the whole of the system of which we are part".

While referred to as a new worldview, it is in reality emerging from an amalgamation of ancient worldviews and a new scientific paradigm based on the findings from both classical and new sciences. The past century has seen a number of surprising discoveries which have washed away much of what we thought we knew, leaving behind both more knowledge and many more questions. A number of these discoveries had to do with our basic assumptions about how the world works and the place of humans in the world. From these discoveries it has become clear that the reductionist scientific paradigm of Bacon, Newton and Descartes that dominated the world since the Enlightenment, does not adequately explain all of reality, especially in the realms of living systems and the sub-atomic world physics. In fact, it would appear that until the development of ecology and quantum physics, earlier paradigms, such as found in Eastern philosophy and indigenous knowledge systems, have been more accurate in their understanding of how living systems and existence at its most foundational level function. 
In order to understand how this new worldview will change the way we deal with the problems of our time, it is necessary to provide an understanding of the worldview itself: how it describes the way the world works and how humans should engage with the world so that their intentions coincide with the way the world works and enable the regeneration of its systems. In this paper we explore the ecological worldview and the guidelines it provides for how we interpret sustainability, as well as the strategies for the production of the built environment we need to follow if we are to adapt to the coming changes in the planetary system and regenerate the world.

\section{Methodology}

The paper synthesizes the findings of two separate studies. The first study (Du Plessis, 2009) is an extensive literature review that used a combination of critical theory, grounded theory and wide reflective equilibrium in an iterative process to define the meta-narratives of the ecological worldview according to a worldview framework proposed by the Centre Leo Apostel (Aerts et al., 2007). This framework was populated through four rounds of reading that provided input from multiple perspectives and sources of knowledge, as well as preceding worldviews (as described in Figure 1). The source of data for the study was a wide range of both representative and seminal texts, and texts that challenge mainstream perspectives, spanning different disciplines, discourses and knowledge sources - in total over nine hundred texts spanning three thousand years of recorded knowledge generation and much older oral traditions were analysed.

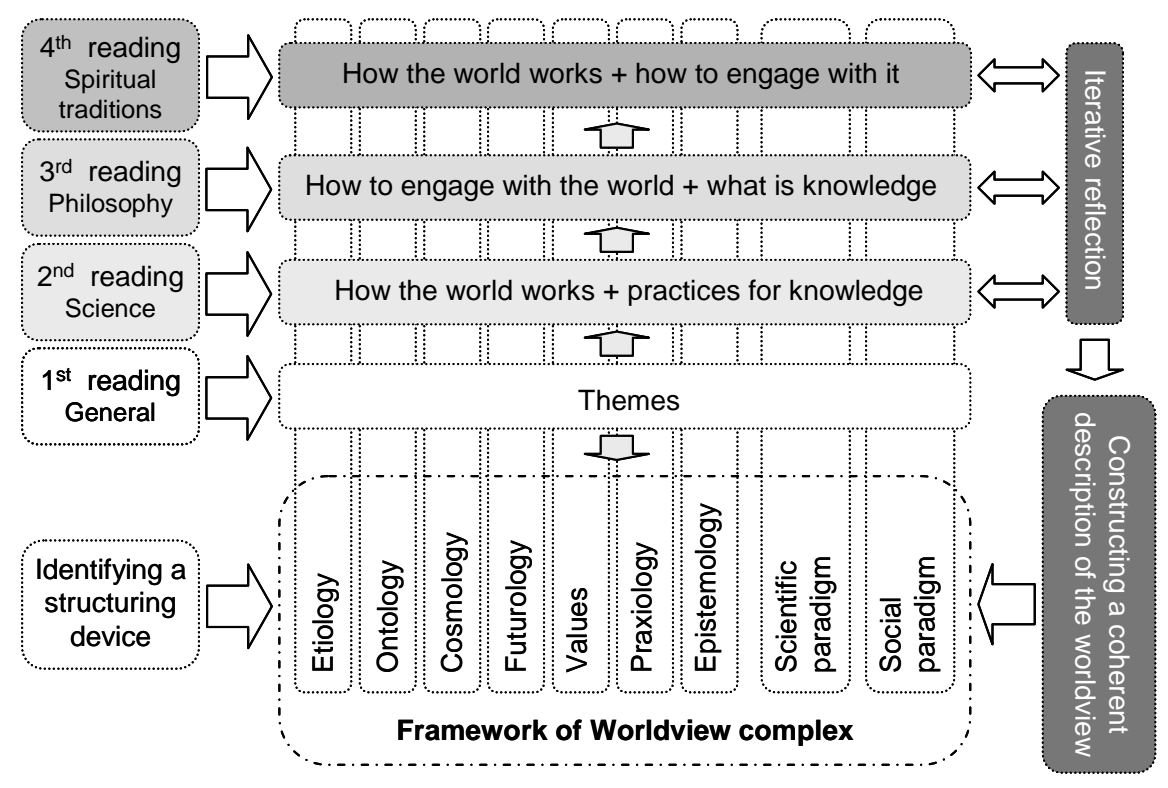

Figure 1: Process for defining a worldview

A first reading of key sources defining the emerging ecological worldview (e.g. Capra, 1983, 1997; Berry, 1990; Rees, 1999; Wilber, 2000a Sterling, 2003; Lazlo, 1987) identified certain themes (categories) within each of the aspects of the worldview complex. These themes were then used to identify additional literature and knowledge sources and further structure the reading. A second reading drew on 21st century science, particularly theoretical physics and complexity science, ecology and other life sciences, and neuroscience. These provided a current scientific understanding of how the world works and practices for generating knowledge. A third reading drew on Eastern and Western philosophical traditions, providing a reasoned understanding of how the world works, how one should engage with such a world and what would constitute knowledge. The fourth and 
final reading drew on spiritual traditions, especially ancient traditions found in indigenous knowledge systems in Africa, Australia, the Americas and pre-Roman Europe. This provided an understanding of how the world works and how one should engage with this world, based on an experiential understanding that has stood the test of time, in some cases (such as Australian aboriginal traditions) for at least 40000 years. Each of these layers added to and reinforced an emerging picture of the world. The last step was an iterative process of reflection and validation through external review that made this picture explicit in a coherent description of the worldview.

The second study (findings of which to be published as Hes and Du Plessis, 2015) provided empirical data, using qualitative content analysis to analyze fifty two in-depth interviews with academics and built environment practitioners identified as working from within an ecological worldview. Participants were identified based on their contribution within the literature (publication and citation in peer reviewed highly referenced journals) and built environment (well known in the industry for their regenerative and innovative work). This analysis aimed to find correlations between the practice and theoretical positions of the participants and the values and praxiology of the ecological worldview as described in the first study. The specific approach is defined as directed content analysis in which initial coding starts with a theory or relevant research findings with the aim to validate or extend a conceptual framework or theory (Zang and Wildemuth, 2009).

\section{Worldviews and paradigms}

While the terms 'worldview' and 'paradigm' are frequently used as fully interchangeable synonyms in the popular literature, they can also be viewed as a way of looking at the world (worldview) that requires a specific set of tools to study the phenomena of this world from this particular perspective (the associated scientific paradigm).

A worldview can be defined as a coherent collection of concepts, theorems, images and basic assumptions that provide an image of and way of thinking about the world (Kearney, 1984:41; Aerts et al., 2007:8). It describes the structure, function and nature of the world, and provides guidance on the general principles by which we should organise our actions within this world: how we are to act and create, and how we can influence and transform the world. As such it not only engages with our scientific understanding of the world, but also with our value systems and ideologies, as well as our ideas about sense-making, problem-solving, decision-making and correct action based on how we evaluate reality and the possible futures to which these actions may lead. It is therefore far more than a scientific explanation of the physical universe.

While a worldview is a coherent image derived from inner experience, practical interaction and interpretation of history and of scientific knowledge (Aerts et al., 2007:9), it is limited by its ontological and epistemological boundaries, and is therefore not necessarily accurate. Thus every worldview adopted as the basis from which to study the phenomena of the world reveals only partial knowledge of the world as it describes only what it can see through its particular lens. This does not mean that the knowledge it provides is suddenly no longer valid when a different worldview is applied (e.g. the laws of classical physics still apply at the relevant scales), or that this knowledge is somehow inferior. However, the knowledge is only partially valid as it describes only those phenomena that can be observed using the tools of analysis (the scientific paradigm) that support that specific worldview. Wilber (2000c:58) further suggests that any new worldview builds 
on the knowledge and insight accumulated through numerous preceding worldviews, but adds its own insights to increase the scope and coherence of the picture being revealed by the accumulated knowledge and wisdom of all these worldviews.

A paradigm can be seen as providing the practices for studying the world from within a particular worldview. Kuhn describes a scientific paradigm as "the set of scientific achievements that for a time provide model problems and solutions to a community of practitioners" (Kuhn, 1970:10). It is the paradigm that discloses a particular type of data and in a way thus determines what data gets disclosed, and therefore the type of knowledge that could be articulated in a given worldspace (the perceivable phenomena) or worldview (Wilber, 2000a:283). Science progresses because cumulative paradigms disclose more and more data of different kinds. Capra (1997:6) further extends this definition to introduce the concept of a social paradigm, which he describes as "a constellation of concepts, values, perceptions and practices shared by a community which forms a particular vision of reality that is the basis of the way the community organizes itself".

\subsection{Moving from the mechanistic to the ecological}

Much has been written about the differences between the currently dominant 'mechanistic' worldview and its counterpart, the emerging 'ecological' worldview, and it has indeed become common practice to start any discussion on both the emerging worldview and its particular variant of sustainability by contrasting it with the mechanistic. While Frijtof Capra's work (especially 1997) is cited most often in this regard, a number of other commentators (Rees, 1999; Elgin and Le Drew, 1997; Wheeler, 2004) have also attempted to define this emerging worldview through contrasting it with the mechanistic. The danger of this approach is that it is easy to fall in the trap of 'mechanistic bad, ecological good', thus perpetuating the dichotomies and dualities that this new worldview professes to end.

Working from Wilber's hypothesis that worldviews evolve by including and transcending preceding worldviews (2000c:58), it is proposed that the ecological paradigm does not negate or replace the mechanistic paradigm, but adds to the knowledge base by providing a different perspective which reveals different types of knowledge, with both of these worldviews providing valuable insights when applied within the appropriate context of analysis and its realm of validity. The knowledge and laws revealed by the mechanistic worldview are still immensely useful when it comes to engineering and technology. However, it has proven to be ineffective, if not outright destructive, when applied to the design and development of living systems, as anthropogenic climate change is illustrating.

\subsection{The ecological worldview summarised}

From the observable qualities of the world as revealed by sciences ranging from quantum physics, systems thinking and ecology, to neuroscience, psychology and sociology, three main narratives can be identified. The first is the need to consider the world as a whole - an interdependent and interconnected living system in which humans are an integral part of nature and partners in the processes of co-creation and co-evolution. Humans, their social structures, and their biophysical environment, form one integrated social-ecological system in which humans and their artefacts are an indivisible part of the biosphere and they, like any other organism, participate in and co-create the metabolic and change processes that shape the biosphere. However, the addition of the human 
mind introduces properties of self-reflection and symbolic thought that allows the intentional creation of novelty and the ability to direct change within the system (Du Plessis, 2008).

The second is that the ecological worldview is first and foremost a relational view. Capra (1997) suggests that while the ecological worldview draws on an understanding of nature and its processes and relationships, it is a much broader concept than that encapsulated in classical ecology or even ecological economics. Implied in 'ecological' is an understanding that we are dealing with living systems and all that comes with such systems, including connections, flows, relationships, interdependence, evolution and consciousness. The ecological worldview sees the phenomenal world as constantly regenerated through interactions within systems at all scales and levels of existence (physical, intellectual, emotional, social and spiritual). These interactions result in and from flows of matter, energy, information and influence, as well as processes of adaptation and selforganisation, which in turn allow these systems to evolve. In this world, phenomena do not exist independently, but come into being through different types of relationship and the processes they provoke.

A world that is constantly created through the interactions engendered by these processes and relationships, suggests the third main theme: the world is dynamic, ever-changing, and therefore impermanent. Even seemingly permanent phenomena are undergoing constant fluctuations and change at both a micro and macro scale of existence. As these small-scale changes reach certain critical thresholds (or bifurcation points), they introduce changes in the organisation of the system (or phenomenon) at larger scales. Eventually the changes brought about at smaller scales will cascade up the scales and transform the identity of phenomena at even the largest scales until a point is reached where the identity of the phenomenon has changed irrevocably (e.g. the mountain has turned to dust, the star has become a black hole). These changes come about because of interactions in open systems between objects and subjects over time leading to essentially unpredictable and irreversible processes. Because of the inherent complexity and non-linear dynamics found in the systems that constitute the world, the world is not only impermanent and ever-changing, but also largely uncertain and unpredictable. In addition, our knowledge of the world is uncertain, constantly changing and relative to the viewpoint of the observer. Thus, accurate prediction and certainty are elusive goals at best. In such a world it is necessary to be able to respond and adapt to perturbations and fluctuations

From these three themes - wholeness, relationship, and change - a set of values can be inferred that are associated with building and maintaining healthy, mutually beneficial interdependent relationships, and acceptance of change as a necessary condition of life. These themes further suggest that guidelines for effective and ethical action would follow the rules of nature and cooperate with nature to contribute to the wellbeing of the whole system.

\section{Regenerative sustainability}

The values and theory of action of the ecological worldview defines a sustainability paradigm that aligns human development efforts with the creative efforts of nature. This paradigm has the potential to create a future where the damage done to the biosphere and to our social systems has been restored, and people can live in mutually supportive symbiosis with their social and biophysical 
environment (their whole ecological system) - the one nurturing and growing the potential of the other. It is, in principle, "the reconnection of human aspirations and activities with the evolution of natural systems - essentially co-evolution" (Mang and Reed, 2012: 6). In addition, a new scientific paradigm with a specific focus on the problems of sustainability is emerging from this worldview. This transdisciplinary 'sustainability science' (Kates, et al., 2001; e.g. Burns and Weaver, 2008) introduces new ways of thinking, new ways of modelling, new ways of assessment, new methods of analysis, and new ways of dealing with the integration and dependency between the many factors which make up this complex topic.

The key elements of this regenerative sustainability paradigm can be summarized as follows:

- The objective of sustainability is to uphold relationships that sustain the ability of the global social-ecological system to provide not just life-supporting but also life-enhancing conditions for the global community of life. To achieve this, it would be necessary to maintain the wholeness of both local and global systems (i.e. their critical structures, functional integrity, overall health and wellbeing, and capacity for regeneration and evolution), and for human efforts to participate positively in processes of creation, evolution and regeneration.

- Sustainability is about learning how to respond and adapt to, and evolve with, change and surprise, while avoiding changes threatening the life-supporting and life-enhancing capacity of global and local social-ecological systems.

- Sustainability is based on a value system which holds that both people and nature should be treated with respect and in a spirit of fellowship and mutuality, and actions should focus not only on the wellbeing of humans, but on the wellbeing of the entire social-ecological system. This means that humans have a duty of care that requires them to support the wellbeing and evolution of the social-ecological systems of which they are part, and take responsibility for the consequences of their actions.

- Decision-making for sustainability is a reflective process that guides decisions about proposed actions, not by measuring these actions against pre-determined and negotiated criteria and indicators, but by questioning whether the proposed actions uphold the values of the ecological worldview and how it expresses these values, as well as what the possible consequences of an intended action would be across system scales and levels.

- Sustainability initiatives are not goal-driven, but rather reflective responses that allow systems to adapt to changing circumstances, new knowledge and surprise; learning from experience in order to build adaptive capacity and healthy resilience and regenerate themselves by evolving towards more abundant, complex and diverse states.

The question this paper asks is: how does this sustainability paradigm, with its focus on regenerating the whole of the social-ecological system within which we are working, change the way the built environment is produced? We will discuss this by looking at the identified responses to each of the three main themes of the ecological worldview - wholeness, relationship and change.

\section{Dealing with the whole}

As stated earlier, the ecological worldview encourages a shift from dealing with the parts of a system in isolation to dealing with the whole system. But what do we mean by whole? What is it that should be integrated and included into this whole? A foundational principle of the ecological worldview is 
the reintegration that needs to happen between human systems and natural systems. While attempts have been made by ecologists and sociologists to understand how the social aspect of humans can be included in the study of the city as ecosystem, Alberti et al. (2003) pointed out that neither of these sciences can explain how integrated human and ecological systems emerge and evolve, because human and ecological factors work simultaneously at different levels. Calls for a "new integrative ecology that explicitly incorporates human decisions, culture, institutions and economic systems" (Grimm et al., 2000:575) into coupled human-nature systems, now referred to as social-ecological systems, has a number of implications for how stakeholders are identified and where system boundaries are drawn (Du Plessis and Cole, 2011). But introducing the human capacity for reflexive self-awareness also allows us to expand our understanding of the whole to include both interior and exterior modalities of existence (Dooyeweerd, 1955; Wilber, 2000a).

\subsection{Reintegrating humans with nature}

Findings in ecology is supporting the ancient understanding of indigenous knowledge traditions that humans are members of the community of life; living in closely interdependent relationships with other living systems. For example in Aboriginal cosmology, everything and everybody, from all space and all time, is seen as intertwined and interdependent, and all are family (Voigt and Drury, 1997:23). This is more than just a functional or utilitarian interdependence. Nelson (1993:205) describes that for hunter-gatherers

...the intricate weaving together of nature and culture is like the exchange between living cells

and their surroundings: the vital breathing in and out, the flux of water and nutrients, the comminglings of outer world and inner flesh.

Thus humans cannot be seen as separate from nature - they and their habitats ARE nature as much as other 'ecological engineers' such as beavers, coral polyps or ant colonies and the habitats they create (Jones, et al., 1999). Therefore, if humans are nature, it would make sense that effective action should follow the laws of nature, cooperate with and participate in the processes of nature, and learn from nature. As lan McHarg (1969:29) pointed out: "the ecological worldview requires that we look upon the world, listen and learn". Approaches such as ecological engineering (Mitsch, 1993), construction ecology (Kibert et al., 2002), building ecology (Graham, 2003), and ecological design (Van Der Ryn and Cowan, 2007) propose the design and construction of mutually beneficial and lifesupporting relationships between built and natural environments, with the built environment following the "non-negotiable laws of nature" (Graham, 2003:8). These approaches are by now, quite well-known, such as the ecological waste water treatment systems or 'living machines' designed by John Todd (Todd and Todd, 1993).

Biomimcry (Benyus, 2002) suggests three ways of learning from nature that can be used in the production of the built environment. The first uses nature as model - i.e. look for precedents in nature that can inspire technology and manufacturing processes that are more life-friendly and abide by the laws of nature. McDonough and Braungart (2002:90) describe these as a series of design assignments that challenge society to develop, for example, buildings and industries that produce more energy than they consume and purify their own waste water, and materials and products that at the end of their useful life can be returned to either natural cycles of decomposition or industrial cycles of re-use. 
The second way is to use nature as a measure, providing "a standard to judge the rightness of our innovations". Criteria such as that set by the Living Building Challenge (Living Futures Institute, 2011) and Positive Development (Birkeland, 2008) that require projects to measure themselves against the positive contribution they make to the functioning of ecosystems, can be considered using nature to judge the rightness of the innovation. The third way is to look at nature as a mentor, extracting its wisdom not just for technological use to improve human life, but also to guide the development of supporting social systems. Benyus (2002:49) uses the example of Natural Systems Agriculture (which includes practices such as permaculture) as an example of an approach that uses the "genius of place" to inform not just human practices and technology, but a specific ethical and normative context that shapes a way of life.

Reintegrating humans with nature requires not just the integration of human technology into ecological processes, but the cognitive, emotional and spiritual reconnection of humans to nature as a vital step to restoring both planetary health and the health of our societies. The Biophilia hypothesis of Edward O Wilson (1984) suggests that humans have a deep need for affiliation with life and life-like processes. Subsequent research (Kellert et al., 2008; Ulrich, 1984) has revealed the close links between psychological and physiological recovery and health, and access to nature. The built environment can through its design and production contribute to restoring and enabling this psychological connection. Biophilic design (Kellert, 2008) includes aspects such as the inclusion of environmental features (plants, water, natural materials, views and vistas to natural landscapes) and natural shapes and forms; introducing natural light and light with qualities found in nature such as the diffuse light in forests; and evolved human-nature relationships made possible by eliciting emotions such as fear, awe, reverence, curiosity, safety and attraction.

An excellent example of biophilic design at work to restore individual, community and ecological health, is the Khoo Teck Puat Hospital in Yishun, Singapore. Designed by CPG Consultants Pte Ltd and opened in 2010, it was planned as a "hospital in a garden and a garden in a hospital" (Alexandra Health Systems, 2013). The main hospital is built around a large forested courtyard with a rainwaterfed stream that connects to the adjoining Yishun Pond. Planters line the open walkways and balconies and images of nature can be found everywhere in the enclosed interior corridors. The hospital management further encourages the link between humans and nature through initiatives such as public information boards documenting the on-going increase in biodiversity enabled by the hospital's many green spaces. At the beginning of 2014, 79 fish species, 35 species of butterfly, 43 bird species, and 21 species of dragonfly have been observed on the hospital grounds, according to these information boards. The hospital itself has added an amount of green surface that is more than six times the size of the land on which the hospital sits (Kishnani, 2012). The Khoo Teck Puat Hospital also introduces two other aspects of wholeness - the integration of the interior and the exterior aspects of social-ecological systems, and the dissolution of fixed boundaries between the building as object and the social-ecological system within which it is situated.

\subsection{Dissolving boundaries}

The ecological worldview sees a world structured according to an order of increasing wholeness, where the whole of one level becomes a part of the next level in ever fewer systems of increasing depth and complexity (Wilber, 2000c:24). Thus a building is a system situated in larger ecological and

social systems that it influences in some way, but is also influenced by. Haggard (2012) further 
describes a building as a temporary nexus in the flows of energy, people, materials, ideas, and so forth. This perspective forces the designer and developer to look beyond the physical boundaries of the object to its role in the regulation, strengthening (or weakening) and integration of these flows. In a regenerative paradigm the building is therefore no longer seen as an isolated high-performance object, but rather as a catalyst for larger systemic regeneration and transformation asking, as developer Robert Mang (pers. comm., 2012) explains: "what it is that I can produce that actually generates more in the community?" An example is the development of the Brattleboro Co-op in Vermont which started as a project to design a LEED Gold grocery store, but rippled into the larger social-ecological system to regenerate the local agricultural system by restoring soil, building a new market for small producers, and providing access to both finances and food processing infrastructure (7Group and Reed, 2009).

\subsection{Integrating the interior and exterior aspects of existence}

To date much of the work of sustainable building has focused on the exterior, or perceptible, realms of the biophysical world and social structures such as legislation or economic systems. However, this only addresses a part of the system. A whole-systems approach fully considers the interpenetrating physical (external, tangible, visible) and mental (internal, intangible, invisible) domains of existence experienced at individual and collective levels across scales of space and time within a socialecological system (Wilber, 2000a). Applied to the built environment this approach brings together the two aspects of a city identified by St Isidore of Seville (c. AD560-636) in his Etymologies (described in Arida, 2002:xix): the urbs (the physical aspects) and the civitas (the emotions, rituals and rules), in an understanding of the city as a phenomenon originating from and created by both mental-social and technological-natural processes. This would require that the conceptual and other models used to inform systemic planning and design processes also account for the flows between interior aspects (e.g. individual and social value systems) and both interior change (e.g. a shift towards a specific value system such as environmentalism) and exterior change (e.g. changing value systems driving the development of environmentally friendly technologies).

Further to this, integral thinking as proposed by Wilber (2000a) suggests that a fully integrative model of the world would include four perspectives: a) the individual interior (e.g. thoughts, feelings, ideals); b) the exterior structure and behavior of the individual; c) the collective interior of the social system (e.g. norms, standards, value systems, shared identities); and d) the perceptible expression of this collective interior in a collective exterior (ritual, technology, economic systems). DeKay (2011) suggests that each of these perspectives holds a different intention for both the form of the built environment and the criteria for what constitutes good form. The individual interior would be experiencing the built environment through subjective aesthetic appreciation and psychological responses to, for example, connection to place. The individual exterior would relate to the building itself and its physical design and performance. A regenerative design approach such as biophilic design can be both the result of the interior need of the designer or client for affiliation with nature, and result in a corresponding regenerative interior experience for the users of such a building. Similarly, designers, clients or users with a strong ecological worldview would foster the production of a built environment that would express the values of this worldview. The same would hold true of the relationship between cultural attitudes and ethics and the creation of the built environment. 
One of the strongest themes that emerged from the interviews was the need to engage with the development and transformation of the interior perspectives of the system, starting with the individual. Regenerative design literally requires a new mind (Mang and Reed, 2012): a new way of seeing and being in the world. Practitioners working from an ecological worldview find themselves compelled to consciously and continuously reflect on the integrity with which they express their ecological values through their actions and behavior, and develop their own ability to respond to the world in a way that will allow it to grow its potential. As Bill Reed (pers. comm., 2012) explains: "It's not just about making ourselves better people, it's that the work I want to do in the world is requiring me to face this thorny issue". This engagement with interior perspectives also underlies the need for stakeholder engagement at a deep level, firstly to build a shared vision through processes that surface and integrate common values while respecting different viewpoints; secondly to build the "capability and field of commitment"(Mang and Reed, 2012:28) that would enable stakeholders to act as both co-designers and future stewards of the project; and thirdly to stimulate the on-going development and transformation of the stakeholders themselves.

Reintegrating the aspects of the system that have been separated within the mechanistic worldview (humans and nature, interior and exterior) allows us to consider the whole of the system in design and development processes. However, for the system to be whole (healthy and functioning), it is necessary to also work on our own development, "as well as participating and being aware of how we are in relationship with other living systems so that their development can be meaningful to them" (Reed, 2012).

\section{Managing relationships}

The second main theme of the ecological worldview is the importance of relationship. McDonough and Braungart (2002:122) describe how each inhabitant of an ecosystem is interdependent with the others: "every creature is involved in maintaining the entire system; all of them work in creative and ultimately effective ways for the success of the whole... in a way that replenishes, restores and nourishes the rest of the world". As the notion of interdependent relationships is fundamental to the ecological worldview, most of the values of this worldview (Du Plessis, 2013; Murray, 2011) are associated with building and maintaining healthy, mutually supportive and mutually beneficial relationships between the self and the 'extended' self, i.e. the rest of the human and non-human community of life and the planet as a whole. According to these values, it is important to maintain the integrity and harmony of these relationships, to ensure that interactions are of mutual benefit, and to take responsibility for the well-being of the whole.

Tools such as metabolic flow analysis and systems dynamics allow an analytical understanding of the relationships and exchanges of resources, power and information in the system. However, they are not sufficient when the aim is to build harmonious and mutually beneficial relationships within the social-ecological system. The Santa Fe based Regenesis Group offers a relationship-based method for the development and design of built environment system interventions (such as buildings or infrastructure). This methodology looks at relationship from three perspectives. The first is to understand the project's right relationship to place. This entails doing an assessment that captures the whole of the system (or place) - that is, the cultural, economic, geographic, climatic and ecological aspects of not only the site, but also the systems within which it is situated, in order to understand the patterns organizing the relationships and dynamics of the place. From these patterns 
a Story of Place is developed that allow stakeholders to see themselves in relationship to the unique character of the place, and to identify leverage points in the system where small initiatives can catalyse beneficial changes in the system(Mang and Reed, 2012). This process allows the developer and the project team to think about the possible mutually beneficial impacts the project can have on the larger system, but also builds a relationship with other stakeholders based on shared understanding of the possibilities of the place. This leads to the second perspective, in which stakeholders collaborate to develop a design that is based on commonly-agreed on guidelines and principles and informed by a joint understanding of what the potential of the project is to enable regeneration.

This carefully facilitated process allows the co-creation of the project in such a way that the design concept reveals a greater potential for both the project and its place and that there is a core team of stakeholders who will contribute to hold the vision of this greater potential long after the design and development team has departed. The third perspective on relationship flows from this need to ensure the on-going functioning and evolution of the project and its regenerative relationship to its place. This is done by growing the capacity of local stakeholders by turning them into 'partnergardeners' with a sense of belonging and caring for their place, who are inspired by the vision of what the full potential could be and have the skills in living systems thinking that will enable them to in future weave together changing patterns in these relationships so that the project can continue to create the conditions for the on-going health and regeneration of the place (Mang and Reed, 2012).

Thus the process of production expands from the production of a product, to include also the production of relationships and capacities within the stakeholder system, as well as the 'production' of increased potential in the system - whether that is the creation of jobs, an increase in biodiversity or ecosystem services, or a healthy society.

\section{Responding to change}

The third theme of the ecological worldview is the idea of change as the only constant. The idea of impermanence is well established in most religious and philosophical traditions. The dance of the Hindu deity Shiva which embodies the moving force of the universe and its constant acts of creation, preservation, destruction, embodiment and release (Singh, 1991:21), is echoed by the Biblical notion that "to everything there is a season" (Ecclesiastes 3:1), and the proposition of Greek philosopher Heraclitus that though things "may appear to be stable, they are actually in an endless process of becoming, in a state of constant flux" (Thilly, 1993: 32). This propensity for change is also supported by sciences such as quantum physics, complexity and ecology.

However, as Mortensen (2006:7) explains, one of the most impenetrable philosophical problems posed by change is that of "persistent identity through change", and more particularly, "how does a thing persist through changes in its intrinsic properties"? Research in chaos theory, complexity science and the resilience of ecological systems explores this question further by (1) trying to understand how phenomena such as the weather, traffic, the stock exchange or ecosystems stay within 'regimes' with a certain identity, even though there are constant fluctuations within these systems (thus creating order in the chaos); and (2) by trying to identify at what point a system transforms to a fundamentally different identity - i.e. at what point a river is no longer a river, or a forest no longer a forest. 
The concept of resilience as adaptive or transformative capacity in the system is gaining prominence in debates on responding to change in the built environment; especially to predicted changes as a result of climate change, but also to other pulse or pressure perturbations in the system such as terrorist attacks or pervasive poverty and inequality. There are many competing definitions of resilience, depending on whether one comes from an engineering, psychological or ecological point of view, but it boils down to the ability of a system to absorb or adapt to change without changing to another stable state described by different variables or a different structure that gives it a different identity. Davoudi (2012) differentiates between resilience that describes a system's ability to return to the status quo or pre-disturbance state (prominent in engineering and disaster management); ecosystem resilience which describe the magnitude of disturbance a system can absorb while remaining within a permissible range of fluctuation that allows it to survive; and the resilience found in social-ecological systems which acknowledges that complex social-ecological systems adapt, transform, and evolve in response to external perturbations and internal stresses and growth. While all three types of resilience have a role to play in the on-going functioning of the built environment, it is particularly the last resilience perspective that supports a regenerative sustainability paradigm.

Resilience thinking presents some useful metaphors and heuristics for understanding the processes of change in urban environments and the vulnerabilities of these systems. The adaptive cycle, a progression of release, reorganisation, rapid growth and conservation resulting in an accumulation of potential that eventually triggers another release phase (Holling and Gunderson, 2002), is useful for understanding cycles of urban decay and regeneration and traps such as institutional inertia or locked-in capital (Pelling and Manuel-Navarrete, 2011) that maintain perverse urban conditions such as low service delivery; but also for identifying leverage points where potential can be released to enable a reorganisation and renewal of the urban system. System characteristics that influence resilience such as functional and response diversity, degrees of connectivity, flexibility, redundancy and tightness of feedback (Walker and Salt, 2006), are being explored for their usefulness in the design and management of the urban system at various scales. For example, Salat (2011) applies these characteristics to urban morphology to determine vulnerabilities in the structure of the city, while Nicol and Knoepfel (2014) apply the notion of flexibility and redundancy to institutional capacity to support the sustainability of housing stock.

Dealing with change and uncertainty also requires the development of different types of assessment and evaluation tools Present models used for assessing sustainable development can be criticised as being too prescriptive and deterministic, skewing assessments towards a preordained objective; and with a language and structure which relate to an industrial and technological age dominated by economic and resource efficiency imperatives. Instead, assessment and evaluation within the regenerative paradigm should be able to monitor change and the capacity for adaptation, and assess whole system performance, i.e. the on-going contribution (positive and negative) to the health and resilience of the larger scale system (or place) in which a project is situated(Du Plessis and Cole, 2011). Brandon and Lombardi (2011, p.26) suggest that any evaluation in this field should be holistic, harmonious, habit forming, helpful (not too complex), hassle-free, hopeful (seek solutions) and be humane (assist the development of human beings without pain, suffering or undue anxiety). These tools should be used to encourage the understanding of inter-dependence and relationships through 
multi- and trans-disciplinary collaboration, and not reinforce the prejudices and bad habits of the past.

\section{Conclusion}

This paper provided a broad outline of a sustainability paradigm that sees the production of the built environment as a means of regenerating, co-creating and evolving social-ecological systems from the local to the global scale. This paradigm flows from a relational worldview encompassing the crossscale complex and adaptive dynamics of the whole living system that is our world, and which transcends old dualities (mind and matter, humans and nature, change and persistence). It is suggested that the purpose of this sustainability paradigm is not to conserve the status quo, but to strengthen the health, adaptive capacity, and evolutionary potential of the fully integrated global social-ecological system so that it can continue regenerating itself, thereby creating the conditions for a thriving and abundant future - not only for the human species, but for all life. This has several implications for the production of the built environment - for how it is created, the technologies used, and how it is evaluated.

Firstly, the process of design and construction expands to become a process of co-creation that continues long after the construction or the physical product (building or infrastructure). What is created is not just an object, but also a wave of change - a ripple that restores, regenerates and opens up new opportunities for growth and development within communities and their ecosystems. Secondly, the technologies, design strategies and materials used aim to reintegrate human habits and habitats with nature - not merely reducing negative impacts, but merging and working with nature to produce a net positive impact. And thirdly, assessment and evaluation tools shift from being competitive and/or compulsory performance measurement systems, to decision-making and monitoring tools based on a growing understanding of system dynamics and feedbacks - tools for reflection that enable the making of wise decisions.

As illustrated, many of the tools and strategies necessary to support a regenerative sustainability paradigm are already there, even if in embryonic form. The challenge is to avoid the trap of trying to find solutions from within the same thinking, the same tools, and the same worldview that caused the problems in the first place, as Einstein warned; and actively embrace, enable and encourage the use and further development of these tools. However, to do so requires not just a new mind, as Mang and Reed (2012) suggests, but also a new heart. This paper therefore seeks to encourage the community of practitioners, researchers, educators, governments, and the general public to adopt a value driven system of production which deals with the whole, reintegrates humans with nature, dissolves traditional boundaries and integrates the interior and exterior aspects of existence for the benefit of all mankind. The question no longer is how to reduce the negative impact of our actions, but instead how each and every action can contribute to a positive future.

\section{Acknowledgements}

The financial assistance (Grant no. 78649) of the South African National Research Foundation (NRF) toward the research is hereby acknowledged. Opinions expressed and conclusions arrived at, are those of the authors and cannot be attributed to the NRF. We would also like to thank Dr Dominique Hes from the University of Melbourne for her invaluable contribution to conducting and analysing the interviews. 


\section{References}

7group and Reed, B. (2009) The Integrative Design Guide to Green Building: Redefining the Practice of Sustainability. Hoboken, NJ: John Wiley \& Sons.

Aerts, D., Apostel, L. De Moor, B., Hellemans, S., Maex, E., Van Belle, H., Van der Veken, J. (2007). World Views. From Fragmentation to Integration. Brussels: VUB Press. Internet edition. Accessed: 02/02/08 from http://www.vub.ac.be/CLEA/pub/books/worldviews.pdf

Alberti, M., Marzluff, J.H. Shulenberger, E., Bradley, G. Ryan, C. \& Zumbrunnen C. (2003). 'Integrating humans into ecology: Opportunities and challenges for studying urban ecosystems.' Bioscience, 53 (12):1169-1179.

Alexandra Health Systems. (2013) A Healing Space. Creating Biodiversity at Khoo Teck Puat Hospital. Singapore. Alexandra Health Systems Corporate Communications.

Arida, A. (2002). Quantum City. Oxford: Architectural Press.

Berry, T. (1990). The dream of the earth. San Francisco: Sierra Club Books.

Birkeland, J. (2008) Positive Development: From vicious circles to virtuous cycles through built environment design. Earthscan, UK.

Brandon P. \& Lombardi P. (2011). Evaluating Sustainable Development in the Built Environment. Oxford: Wiley-Blackwell.

Burns, M. \& Weaver, A. (Eds.) (2008). Exploring sustainability science - A Southern African perspective. Stellenbosch: Sun Press.

Capra, F. (1983). The Tao of Physics. London: Flamingo.

Capra, F. (1997). The Web of Life. London: Flamingo.

Davoudi, S. (2012). Resilience: a bridging concept or a dead-end? Planning Theory \& Practice, 13(2):299-333.

DeKay, M. (2011). Integral Sustainable Design - transformative perspectives. London \& Washington, DC: Earthscan.

Du Plessis, C. (2008). A Conceptual Framework for Understanding Social-Ecological Systems. In Burns, M. and Weaver, A. (eds.) Exploring Sustainability Science - A Southern African Perspective. Stellenbosch: Sun Press. pp.59-90.

Du Plessis, C. (2009). An approach to studying urban sustainability from within an ecological worldview. Unpublished doctoral thesis, University of Salford.

Du Plessis, C. and Cole, R.J. (2011). Motivating stakeholders: Changing the paradigm. Building Research and Information, 39(5): 436-449.

Du Plessis, C. (2013). Using the long lever of value change. In Crocker, R and Lehmann, S. (eds.) Motivating Change: Sustainable Design and Behaviour in the Built Environment, Oxon, UK: Routledge Earthscan series. pp. 92-108.

Edwards, A. R. (2005). The sustainability revolution: Portrait of a paradigm shift. Gabriola Island, BC, Canada: New Society Publishers. 
Elgin, D. \& Le Drew, C. (1997). Global consciousness change: Indicators of an emerging paradigm, California: Millennium Project.

Graham, P. M. (2003). Building ecology. First principles for a sustainable built environment. Oxford: Blackwell Science Ltd.

Grimm, N. B., Grove, J. M., Pickett, S. T. A., Redman, C. L. (2000). 'Integrated approaches to longterm studies of urban ecological systems.' Bioscience, 50(7):571-584.

Hes, D. and Du Plessis, C. (2015). Designing for Hope: pathways to regenerative sustainability. Oxon, UK: Routledge Earthscan.

Holling, C. S. \& Gunderson, L. H. (2002). Resilience and adaptive cycles. In Gunderson, L. H. \& Holling, C. S. Panarchy. Understanding transformations in human and natural systems. Washington DC: Island Press. pp. 25-62.

International Living Future Institute. (2012). Living Building Challenge 2.1: A Visionary Path to a Restorative Future. Seattle, WA: International Living Future Institute.

Jones,C.G., Lawton, J.H. and Shachak, M. (1994).Organisms as Ecosystem Engineers. Oikos: 373-86.

Kates, R. W., Clark, W. C., Corell, R., Hall, J. M., Jaeger, C. C., Lowe, I., McCarthy, J. J., Schellnhuber, H. J., Bolin, B., Dickson, N. M., Faucheux, S., Gallopin, G. C., Gruebler, A., Huntley, B., Jäger, J., Jodha, N.S., Kasperson, R. E., Mabogunje, A., Matson, P., Mooney, H., Moore, B., O'Riordan, T. \& Svedin, U. (2001). 'Sustainability science.' Science, 292:641-642.

Kearney, M. (1984). Worldviews. Novato, CA: Chandler \& Sharp Publishers.

Kellert S.R. (2008). Dimensions, Elements, and Attributes of Biophilic design. In Kellert, S.R., Heerwagen, J.H. and Mador, M. (Eds.) Biophilic Design: The Theory, Science and Practice of Bringing Buildings to Life. New York: John Wiley \& Sons. pp. 3-20.

Kellert, S.R., Heerwagen, J.H. and Mador, M. (2008). Biophilic Design: The Theory, Science and Practice of Bringing Buildings to Life. New York: John Wiley \& Sons.

Kibert, C. J., Sendzimir, J. \& Guy, G. B. (2002). Construction ecology - Nature as the basis for green buildings. London and New York: Spon Press.

Kishnani, N. (2012). Greening Asia. Emerging Principles for Sustainable Architecture. Singapore: BCI Asia.

Kuhn T (1970). The Structure of Scientific Revolutions ( $2^{\text {nd }}$ edition), Chicago: University of Chicago Press.

Lazlo, E, (1987). Evolution: The grand synthesis. Boston: Shambala.

Mang. P. and Reed, B. (2012). Designing from place: a regenerative framework and methodology. Building Research \& Information, 40:1: 23-38

McDonough, W. \& Braungart, M. (2002). Cradle to cradle. New York: North Point Press.

McHarg, I.L. (1969). Design with Nature. New York: Doubleday.

Mitsch, W. J. (1993). 'Ecological engineering - A cooperative role with the planetary life-support system.' Environment, Society \& Technology, 27(3):438-445. 
Mortensen, C. (2006). Change. In Zalta, E.N. (Ed.), The Stanford Encyclopaedia of Philosophy (Winter $2006 \quad$ Edition). Accessed 25/04/2008 from http://plato.stanford.edu/archives/win2006/entries/change

Murray, P. (2011). The Sustainable Self: A Personal Approach to Sustainability Education. London: Earthscan

Nelson, R. (1993). Searching for the lost arrow: Physical and spiritual ecology in the hunter's world. In Kellert, S. R and Wilson, E. O. (Eds.) The Biophilia Hypothesis. Washington D.C.: Island Press. pp. 201-228.

Nicol, L.A. and Knoepfel, P. (2014) Resilient housing: a new resource-oriented approach. Building Research \& Information, 42(2): 229-239.

Orr, D. (2005). Foreword. In Edwards, A. R., The sustainability revolution - Portrait of a paradigm shift. Gabriola Island, BC, Canada: New Society Publishers.

Pelling, M. and Manuel-Navarette, D. (2011). From resilience to transformation: The adaptive cycle in two Mexican urban centers. Ecology and Society, 16(2), Article 11.

Popper K (1963) Objective Knowledge - An evolutionary Approach, Oxford: Oxford University Press

Popper K (2004) Conjectures and Refutations; the growth of scientific knowledge, Routledge: London.

Reed, B. (2007). 'Shifting from "sustainability" to regeneration.' Building Research \& Information, 35(6):674-680.

Rees, W. E. (1999). Achieving sustainability: Reform or transformation? In Satterthwaite, D, (Ed.), The Earthscan reader in sustainable cities. London: Earthscan. pp.22-52.

Salat, S. (2011). Cities and Forms: On Sustainable Urbanism. Paris: CSTB Urban Morphology Laboratory with Hermann Editeurs des Sciences et des Artes.

Singh, D. V. (1991). Hinduism - An introduction. Jaipur: Travel Wheels.

Sterling, S. (2003). Whole systems thinking as a basis for paradigm change in education: Explorations in the context of sustainability. PhD Dissertation: University of Bath, UK.

Thilly, F. (1993). A history of philosophy. (Revised by Ledger Wood). Allahabad: Central Publishing House. (3 $3^{\text {rd }}$ ed.) First edition: 1951.

Ulrich, R.S. (1984). View through a Window may Influence Recovery from Surgery. Science, 224: 420421

Van der Ryn, S. \& Cowan, S. (2007). Ecological design. $10^{\text {th }}$ Anniversary Ed. Washington, D.C.: Island Press.

Voigt, A. \& Drury, N. (1997). Wisdom from the Earth. East Roseville, NSW, Australia: Simon \& Schuster.

Walker, B.H. \& Salt, D. (2006). Resilience thinking. Sustaining ecosystems and people in a changing World. Washington D.C.: Island Press.

Wheeler, S. M. (2004). Planning for sustainability. London and New York: Routledge.

Wilber, K. (2000a). Sex, ecology, spirituality. $2^{\text {nd }}$ edition. Boston: Shambala. 
Wilber, K. (2000b). A theory of everything. Boston: Shambala.

Wilber, K. (2000c). A brief history of everything. $2^{\text {nd }}$ edition. Boston: Shambala.

Wilson, E.O. (1984). Biophilia. Cambridge, MA: Harvard University Press.

Zhang, Y. \& Wildemuth, B. M. (2009). Qualitative analysis of content. In B. Wildemuth (Ed.), Applications of Social Research Methods to Questions in Information and Library Science. Westport, CT: Libraries Unlimited. pp.308-319. 